\title{
Comprehension of wh-questions in a case of mixed dementia
}

Article

Accepted Version

Salis, C. and Saddy, J. D. (2011) Comprehension of whquestions in a case of mixed dementia. Journal of Neurolinguistics, 24 (2). pp. 456-462. ISSN 0911-6044 doi: https://doi.org/10.1016/j.jneuroling.2010.02.001 Available at https://centaur.reading.ac.uk/4501/

It is advisable to refer to the publisher's version if you intend to cite from the work. See Guidance on citing.

To link to this article DOI: http://dx.doi.org/10.1016/j.jneuroling.2010.02.001

Publisher: Elsevier

All outputs in CentAUR are protected by Intellectual Property Rights law, including copyright law. Copyright and IPR is retained by the creators or other copyright holders. Terms and conditions for use of this material are defined in the End User Agreement.

\section{www.reading.ac.uk/centaur}

\section{CentAUR}

Central Archive at the University of Reading

Reading's research outputs online 


\section{Comprehension of wh-questions in a case of mixed dementia}

Christos Salis

(corresponding author)

School of Psychology \& Clinical Language Sciences

University of Reading, Reading, RG6 6AL, United Kingdom

c.salis@,reading.ac.uk

tel. no. +441183787467

fax no. +441183784693

J. Douglas Saddy

School of Psychology \& Clinical Language Sciences

University of Reading, Reading, RG6 6AL, United Kingdom

j.d.saddy@reading.ac.uk 


\begin{abstract}
We investigated processing of wh-questions and declarative sentences with differing syntactic complexity in a case of mixed dementia (FA). FA was impaired in her ability to understand syntactically complex declarative sentences and syntactically complex wh-questions beginning with which but not complex who questions. This profile, novel in dementia, is similar to that reported for people with agrammatic aphasia and discerns a "fault line" of the language system along a syntactic/semantic parameter.
\end{abstract}

Keywords: mixed dementia, wh-questions, syntax, grammar 


\section{Introduction}

The term dementia refers to neuropsychiatric syndromes of progressive nature, which impair linguistic and non-linguistic cognitive functioning. Prevalent types of dementia are Alzheimer's disease $(\mathrm{AD})$, vascular dementia $(\mathrm{VaD})$ and mixed dementia $(\mathrm{MD})$, the focus of this paper. The characterisation of these syndromes is based on the neurobiological changes that occur in the brain. AD pathology is attributed to amyloid plaques and neurofibrillary tangles, whereas $\mathrm{VaD}$ is due to vascular pathology, e.g. cerebral infarctions (Roman, 2003). The two conditions often co-occur, giving rise to MD (American Psychiatric Association, 1994; Roman, 2003). Many people with AD have a vascular pathology (Neuropathology Group of the Medical Research Council Cognitive Function and Ageing study, 2001; Korczyn, 2002; Langa, Foster \& Larson, 2004) and the vascular element in AD is considered an important aetiological factor by some researchers (de la Torre, 2001, 2002; Korczyn, 2002; Casserly \& Topol, 2004).

The linguistic deficits in dementia are often described as aphasia (Frattali, Grafman, Patronas, Makhlouf \& Litvan, 2000; Maxim \& Bryan, 2006; Bayles \& Tomoeda, 2007). Aphasia usually defines a non-progressive language deficit following brain damage (a definition we use here). One aspect of language that has been investigated in dementia (in particular AD) is syntactic comprehension, and particularly, the so-called subject/object asymmetry. Difficulties understanding reversible, objectextracted (non-canonical) structures, e.g. the boy that the girl is kissing is tall, in comparison with subject-extracted (canonical) sentences, e.g. the boy that is kissing the girl is tall are not uncommon in AD (Grober \& Bang, 1995; Grossman, D’ Esposito, Hughes, Onishi, Biassou, White-Devine, \& Robinson, 1996; Kempler, Almor, Tyler, Andersen, \& MacDonald, 1998; Emery, 2000; Grossman \& Rhee, 2001). Exceptions to this pattern have been reported (Kempler, Curtiss, \& Jackson, 1987; Rochon, Waters, \& Caplan, 2000). Deficits with complex syntactic structures have been reported in other types of dementia such as fronto-temporal degeneration (e.g. Holland, McBurney, Moosy \& Reinmuth, 1985; Grossman et al., 1996) and primary progressive aphasia (Grossman \& Moore, 2005). These patterns are similar to those reported in aphasia (e.g. Caramazza \& Zurif, 1976; Grodzinsky, 2000; Bastiaanse \& Edwards, 2004; Edwards, 2005). The sentence comprehension deficits in AD have been attributed to a genuine syntactic deficit (Grober \& Bang, 1995), working memory limitations that interfere with sentence interpretation (Kempler et al., 1998; Waters \& Rochon, 1998; Rochon et al., 2000), slow information processing restricting the timely realisation of sentence structure and limitations in inhibitory processing of canonical sentence structure (Grossman \& Rhee, 2001). We return to these accounts in the discussion.

The majority of sentence processing research that has been carried out in dementia has focused on declarative sentences. Understanding of wh-questions (questions beginning with who and which) in 
subject- and object-extracted positions has not been investigated ${ }^{1}$. The aims of this paper are: (i.) to document the syntactic abilities in a patient with mixed dementia by investigating understanding of whquestions and declarative sentences; (ii.) to discuss this profile with reference to accounts for the understanding of wh-questions and three accounts of sentence processing that have been postulated in $\mathrm{AD}$, a related type of dementia to MD.

We will first consider some relevant properties of wh-question constructions and their processing. The most salient observation is that the restriction in terms of referent selection in who questions are more open-ended while in which questions they are more fixed. The referents for a who question can be (but are not required to be) non-specific, while in which questions they are specific as evidenced by their relative acceptability in existentials - Who is there in the garden? vs *Which boy is there in the garden? Furthermore who is compatible with singular, plural and list responses. Q:Who wants pizza? A1: Bill, A2: the girls A3: Bill, the girls, the man in the odd hat and me. The options for response to Which $x$ is restricted by the properties of the $x$. A different view relates who and which question to discourse. According to Pesetsky (1987), which phrases refer to a set of referents that have been established in discourse among speakers (hence discourse-linked). Who phrases, on the other hand, do not refer to preestablished referents and are therefore non-discourse-linked. This distinction has prompted recent debates in aphasia (Thompson, Tait, Ballard, \& Fix, 1999; Avrutin, 2000; Balogh \& Grodzinsky, 2000; van der Meulen, Bastiaanse \& Rooryck, 2002; Neuhaus \& Penke, 2008; Salis \& Edwards, 2008). One aspect of the debate is whether there is indeed a discourse basis for the difficulties people with aphasia have with non-canonical questions. Support for the discourse-linked / As a group, and withstanding individual variation, aphasic speakers understand subject-extracted who questions, e.g. who has kissed the boy? and their object-extracted counter-parts, e.g. who has the boy kissed? (Avrutin, 2000; Salis \& Edwards, 2008).

The well-known subject/object asymmetry, common in declarative sentences, does not hold for who but holds for which questions. Object-extracted which questions, e.g. which boy has the girl kissed?, are more likely to be impaired than subject-extracted ones, e.g. which boy has kissed the girl?. In the discourse account object-extracted which questions are costly in a processing sense because which needs a discourse interpretation that is more difficult to achieve than a non-discourse interpretation as in noncanonical who questions (Avrutin, 2000). A different view based on set theory and semantic features of phrases, the set partition hypothesis, has been suggested by Salis and Edwards (2008). The aspect of their account relating to $w h$-questions is that which phrases impose set partitioning demands, in other words, they call for the establishment of restrictive sets of features. This does not occur in who phrases as the sets are open-ended and consequently who phrases have a facilitating effect, even though the listener has to follow the non-canonical order of thematic roles. Set partitioning demands exacerbate processing difficulties. This account helps explain the good performance in non-canonical who questions and poor

\footnotetext{
${ }^{1}$ There is some limited evidence that processing of wh-questions is impaired in posterior cortical atrophy, a type of dementia related to $\mathrm{AD}$ (Salis, in press).
} 
performance in which questions. Both the discourse account and the set partition hypothesis assume a general processing limitation present after brain damage which is exacerbated by which questions and not by who. Both accounts make similar predictions: (i.) no processing differences between canonical, subject-extracted who questions and non-canonical object-extracted who questions; (ii.) processing differences between canonical, subject-extracted which questions and non-canonical object-extracted which questions with the latter type less likely to be understood. Despite these similarities the discourselinking account explains why which questions are likely not to be understood but it does not explain why non-canonical who questions are understood well. A related finding in support of the set partition hypothesis is the following. Passive sentences (another example of a non-canonical sentence) that involve the universal quantifier every, e.g. every boy was pushed by a girl, (Saddy, 1995; Balogh \& Grodzinsky, 2000) are understood better than their non-quantified counterparts. Every, like who, may have a facilitating effect as it denotes an open-ended set of referents. These patterns show that syntactic processing may be spared in brain pathology and reveal that quantificational elements may have an augmentative role in sentence processing which needs further empirical support.

\section{Method}

FA is a 78 year-old woman who has had a medical diagnosis of mixed dementia since she was 77 , although concerns about her memory first arose when she was 76. FA is right-handed and has lived in England most of her life. English is her second yet dominant language. She was educated in an Englishspeaking school and has been exposed to, and used English most of her life. She was married to an English-speaking husband. FA was a medical secretary before retirement. FA's expressive output was fluent with no obvious word finding difficulties and her sentence structure and discourse abilities were judged to be within normal limits during conversation. Short-term memory difficulties were evident in conversation. For example, she would offer tea on several occasions during a visit and she appeared unaware of this. Her understanding of language in conversation was judged to be within normal limits, in the absence of distractions and background noise. No hearing difficulties were noted. Ethical review of the study took place before approaching FA who gave her consent to participate.

FA was assessed in a range of assessments (in the following in order): a digit span task (Wechsler, 1987), the Cognitive-Linguistic Quick Test (CLQT, Helm-Estabrooks, 2001), the comprehension part of the short Boston Diagnostic Aphasia Examination (BDAE, Goodglass, Kaplan \& Barresi, 2001), verb comprehension of the Verb and Sentence Test (VAST, Bastiaanse, Edwards \& Rispens, 2002) and the Mini-Mental State Examination (MMSE, Folstein, Folstein \& McHugh, 1975). Syntactic comprehension was tested on the sentence comprehension subtest of the VAST, which is a sentence-picture matching task. It assesses comprehension of reversible canonical (actives, subject clefts) and non-canonical (passives, object clefts) declarative sentences. This test was administered twice in different sessions (a week apart) to establish stability of FA's performance. 
Comprehension of wh-questions was tested in two act-out tasks. In the first task (task 1) 3 animals (two of the same kind but different in size and a third different animal) were placed in front of FA. Using these animals, the investigator acted out a simple scenario and then a wh-question was asked. FA had to respond by pointing to an animal. The animals were left in front of FA after the scenario. A total of 80 questions were presented in pseudorandom order. There were two types of questions, who and which (see table 3 for examples), either canonical or non-canonical. There was also a padded set which was longer than the first short set containing the adjunct just now was added (see table 3 for examples). This set was included in order to investigate if sentence length influenced comprehension. The second act-out task (task 2) was included to investigate possible task effects. This task was administered in a different testing session. In this task four animals were placed in front of FA, two pairs of a different kind of animal, e.g. two giraffes (small and large) and two hippos (small and large). The investigator acted out two consecutive scenarios before the target question was asked. For example, one of the giraffes was shown to perform an action to one of the hippos, then, the second giraffe performed the same action to the second hippo. The same question types (as in task 1) were used (examples in table 3). Control data for these tasks was elicited from 8 healthy age-matched participants none of whom had a MMSE score of less than 27 out of 30 (cut-off score of below norm performance for the MMSE is 23) (Folstein et al., 1975). 
Table 1 Memory, language and other cognitive abilities

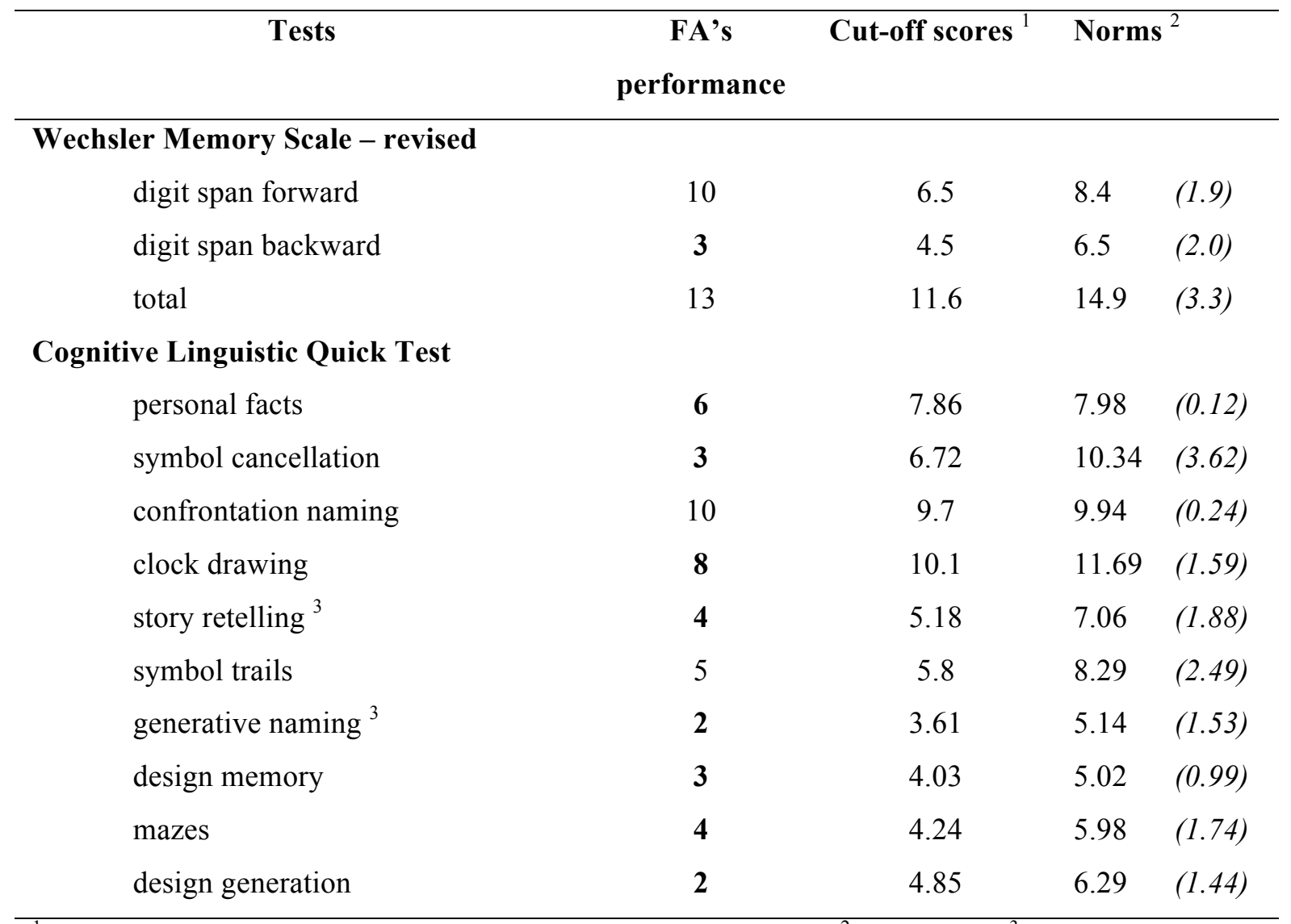

\footnotetext{
${ }^{1}$ based on -1 standard deviation from control mean performance $;{ }^{2}$ mean (s.d.) $;{ }^{3}$ composite score comprising more than one related tasks
} 
Table 2 Performance on wh-questions

\begin{tabular}{|c|c|c|c|}
\hline Canonical & Task 1 & Task 2 & $\begin{array}{l}\text { Tasks } 1,2 \\
\text { combined }\end{array}$ \\
\hline who has bumped the hippo (just now)? & $.90(1.0)$ & $1.0(1.0)$ & $.95(1.0)$ \\
\hline which zebra has bumped the hippo (just now)? & $1.0(.90)$ & $.90(.90)$ & $.85(.90)$ \\
\hline \multicolumn{4}{|l|}{ Non-canonical } \\
\hline who has the hippo bumped (just now)? & $.90(.80)$ & $.80(.90)$ & $.85(.85)$ \\
\hline which zebra has the hippo bumped (just now)? & $.40(.60)$ & $.50(.60)$ & $.45(.60)$ \\
\hline
\end{tabular}


Table 3 Performance on VAST

testing A

testing B

testing A, B

combined

sentence types

actives

subject clefts

canonical total

passives

object clefts

non-canonical total

\begin{tabular}{lll}
\hline $.90(9 / 10)$ & $1.0(10 / 10)$ & $.95(19 / 20)$ \\
$.50(5 / 10)$ & $.70(7 / 10)$ & $.60(12 / 20)$ \\
$.70(14 / 20)$ & $.85(17 / 20)$ & $.78(31 / 40)$ \\
$.60(6 / 10)$ & $.50(5 / 10)$ & $.55(11 / 20)$ \\
$.70(7 / 10)$ & $.50(5 / 10)$ & $.60(12 / 20)$ \\
$.65(13 / 20)$ & $.50(10 / 20)$ & $.58(23 / 40)$ \\
\hline
\end{tabular}




\section{Results and discussion}

FA's performance on the BDAE was as follows: word comprehension 15.5/16, commands, 10/10, complex ideational material, 5/6. Her naming ability on the Boston Naming test was 27/60 correct. Mean performance from control participants is 48.9 (s.d. 6.3). Her ability to name object is impaired. Understanding of verbs was 39/40 (VAST). These results show that apart from object naming, her understanding of single words (nouns and verbs) is within normal limits and so is her ability to understand simple commands and short samples of discourse as well as language relating to semantic knowledge. On the MMSE she had a score of 19 (cut-off score is 23), suggesting a mild deficit in this test of gross cognitive functioning. Table 1 shows FA's performance on various cognitive tasks. The cut-off scores between normal and impaired performance are based on the arbitrary measure of -1 standard deviation from average normal performance on the digit span and CLQT. Impaired scores are shown in bold. Auditory rehearsal (digit span forward, score 10) is within normal limits yet repeating digits backwards (an aspect of executing functioning) is impaired. Autobiographical memory (CLQT, personal facts, score 6) is also impaired. Story retelling requires intact linguistic input and output as well as shortterm memory. Generative naming, a task requiring executive and lexical skills, is also impaired. Given that her lexical retrieval (Boston Naming test) are impaired, it is difficult to decide whether it was executive functioning or lexical retrieval. However, lexical retrieval difficulties were not observed when talking to FA.

FA's performance on the VAST is shown in table 2. The data from testing points A and B were combined. The difference between canonical (.78) and non-canonical sentences (.58) was significant (Fisher exact, $\mathrm{p}=.047$, one-tailed). This pattern conforms to the subject/object asymmetry that has been reported in other studies of dementia (AD in particular) (e.g. Grober \& Bang, 1995; Emery, 2000). FA is statistically more impaired in her ability to understand syntactically complex sentences. This pattern renders some support to the notion of a genuine syntactic impairment suggested by Grober and Bang (1995). In their study, people with AD had difficulties understanding written sentences (reversible passives) in a sentence-picture matching task, even when working memory demands were minimised.

Performance on wh-questions (tasks 1 and 2) is shown in table 2. The data from tasks 1 and 2 were also combined in order to work with larger numbers of observations. The range of scores the control participants achieved in these tasks was $85 \%-100 \%$. FA's performance on short, non-padded, whquestions showed the following (statistical analyses conducted with one-tailed Fisher exact tests): No significant difference between who canonical (.95) and non-canonical (.85) questions; a significant difference between which canonical $(.85)$ and non-canonical questions $(.45)(\mathrm{p}=.009)$. The same pattern was observed in padded questions (performance shown in brackets). So, the difference between who canonical (1.0) and non-canonical (.85) questions was not significant but the difference between which canonical $(.90)$ and non-canonical $(.60)$ questions was significant $(\mathrm{p}=.032)$. The subject/object 
asymmetry that was evident in declarative sentences is only evident in which questions but not in questions beginning with who. This pattern shows a sensitivity not only to object extraction but also to the nature of wh-phrase. The comparison between longer, padded and non-padded sentences was not significant ( $\mathrm{t}(7)=-1.0$ n.s., two-tailed), suggesting that phonological working memory was sufficient to understand the questions that FA listened to. Several researchers have suggested that sentence processing is compromised in AD due to working memory limitations (e.g. Kempler et al., 1998; Rochon et al., 2000). For example, Rochon and colleagues found that syntactic complexity did not alter their participants' comprehension ability but sentences with two propositions did. Furthermore, there was a correlation between working memory executive demands (cf. backward digit span) and number of propositions in their study. FA's gross working memory abilities are within normal limits, if one adds scores from forward and backward digit span task together. Nonetheless, the low score of 3 in the backward digit span suggests difficulties with executive aspects of working memory. However, these difficulties do not interfere with understanding of sentences. Her ability to understand the padded (phonologically longer) sets of questions is similar to that of shorter, non-padded sets. Martin and Miller (2002) note that what is important in sentence processing is the retention of semantic and syntactic interpretations rather than the phonological form of the sentence per se. If FA has a genuine syntactic deficit (cf. Grober \& Bang, 1995), that is, a deficit that affects object-extracted sentences, then the question that arises is why object-extracted who questions are exempt from this deficit.

Grossman and Rhee (2001) proposed that slow information processing restricts the realisation of sentence structure and there are difficulties with inhibitory processing of canonical sentence structure. In the absence of reaction time data we have little to say about the slowness aspect of their account. However, there is evidence that FA's inhibitory ability is not intact. In the symbol cancellation task of the CLQT (table 1), FA had to identify and cross out small sets of patterns that were dissimilar to other patterns on a page. Her score of 3 suggests difficulties with this task. The design generation task also required inhibitory processing (and executive functioning). In this task she had to produce line patterns by joining four dots and making a different design each time. Her score in this task was 2 which also suggests difficulties with inhibitory processing. Out of the 13 designs she produced 8 were copies of designs she had already produced. Similarly, in the generative naming tasks (letter and semantic fluency) she had to produce as many words as she could within one minute. FA was better in semantic fluency (naming animals) and poor on letter fluency (naming words that began with $/ \mathrm{m} /$ ). In semantic fluency, she produced 12 responses but 5 of those were repetitions (i.e. perseverations). There were only two responses in animal fluency. These data suggest aspects of verbal and non-verbal inhibition are impaired. Returning to the wh-questions, it seems that if FA does have a difficulty inhibiting canonical sentence structure, this is selective. It applies to which questions and leaves out non-canonical, object-extracted who questions. Consistent with the set partition hypothesis, we argue that the inhibitory mechanism of suppressing the semantic features that relate to restricted set in object-extracted which questions is defective whereas the inhibitory mechanism in who questions has been spared. This has to do with the 
inherent property of the two types of questions. Who questions require processing of only one larger set which facilitates inhibition of competitors. Which requires processing of two sets, a subset, as well as that of a larger set which make the inhibitory demands greater thus accounting for the erroneous responses.

In this paper we have discussed a patient with MD who has consistent difficulties in understanding non-canonical declarative sentence and non-canonical which questions whereas her ability to understand non-canonical who questions is superior. Although the same pattern of performance has been replicated in different testing sessions, the external validity of this study is limited as FA's profile may not be representative of other cases of MD. Another limitation in this study is that we have no information on FA's site(s) of pathology. Her medical notes did not contain this information. Clinically, the accurate diagnosis of dementia syndromes is a contentious issue with differing opinions and criteria. Nevertheless, as MD pathology has a vascular and an amyloid/neurofibrillary element, it may suggest similar language profiles in other people with $\mathrm{MD}$, or indeed people with a diagnosis of $\mathrm{AD}$ or $\mathrm{VaD}$. From a neurolinguistic perspective, our study shows that the sentence processing deficit in various progressive and non-progressive cognitive conditions suggest similar patterns of breakdown across conditions. The language system seems to fractionate fairly consistently along a syntactic/semantic "fault line" which is influenced by inhibition. We have discussed a novel factor that could inform further investigations of sentence processing in dementia. 


\section{Acknowledgements}

We would like to thank FA fir taking part in this study and her family for their interest in language breakdown in dementia and also Marielle Kay for referring FA. This project was funded by the Dunhill Medical Trust (UK) (R60/0707). 


\section{References}

Almkvist, O. (1994). Neuropsychological deficits in vascular dementia in relation to Alzheimer's disease: reviewing evidence for function similarity or divergence. Dementia, 5, 203-209.

American Psychiatric Association (1994). Diagnostic and statistical manual of mental disorders (4th ed.). Washington, DC: Author.

Avrutin, S. (2000). Comprehension of discourse-linked and non-discourse-linked questions by children and Broca's aphasics. In Y. Grodzinsky, L. Shapiro, \& D. Swinney (Eds.), Language and the brain: representation and processing (pp. 295-313). San Diego: Academic Press.

Balogh, J. E., \& Grodzinsky, Y. (2000). Levels of linguistic representation in Broca’s aphasia: implicitness and referentiality of arguments. In R. Bastiaanse, \& Y. Grodzinsky (eds.), Grammatical disorders in aphasia: a neurolinguistic perspective (pp. 88-104). London: Whurr.

Bayles, K. A., \& Tomoeda, C. (2007). Cognitive-communication disorders of dementia. San Diego: Plural.

Cassely, I., \& Topol, E. (2004). Convergence of atherosclerosis and Alzheimer's disease: inflammation, cholesterol, and misfolded proteins. The Lancet, 363, 1139-1146.

De la Torre, J. C. (2002). Alzheimer's disease as a vascular disorder: nosological evidence. Stroke, 33, 1152-1162.

Edwards, S. (2005). Fluent aphasia. Cambridge: Cambridge University Press.

Folstein M. F., Folstein S. E., \& McHugh P. R. (1975). Mini-mental state: a practical method for grading the cognitive state of patients for the clinician. Journal of Psychiatric Research, 12, 189-198.

Frattali, C., Grafman, J., Patronas, N., Makhlouf, M. S., \& Litvan, I. (2000). Language disturbances in corticobasal degeneration. Neurology, 54, 990-992.

Grober, A., \& Bang, S. (1995). Sentence comprehension in Alzheimer's disease. Developmental Neuropsychology, 11, 95-107.

Grossman, M. \& Moore, P. (2005). A longitudinal study of sentence comprehension difficulty in primary progressive aphasia. Journal of Neurology, Neurosurgery and Psychiatry, 76, 644-649. 
Grossman, M., \& Rhee, J. (2001). Cognitive resources during sentence processing Alzheimer's disease. Neuropsychologia, 39, 1419-1431.

Grossman, M., D’ Esposito, M., Hughes, E., Onishi, K., Biassou, N., White-Devine, T., \& Robinson, K. M. (1996). Language comprehension profiles in Alzheimer's disease, multi-infarct dementia, and frontotemporal degeneration. Neurology, 47, 183-189.

Helm-Estabrooks, N. (2001). Cognitive linguistic quick test. The Psychological Corporation.

Holland, A. L., McBurney, D. H., Moosy, J., \& Reinmuth, O. M. (1985). The dissolution of language in Pick's disease with neurofibrillary tangles: A case study. Brain and Language, 24, 36-58.

Hickok, G., \& Avrutin, S. (1996). Comprehension of wh-questions in two Broca's aphasics. Brain and Language, 52, 314-327.

Kempler, D., Almor, A., Tyler, L. K., Andersen, E. S., \& MacDonald, M. C. (1998). Sentence comprehension deficits in Alzheimer's disease: a comparison of off-line vs. on-line sentence processing. Brain and Language, 64, 297-316.

Korczyn, A. D. (2002). Mixed dementia - the most common cause of dementia. Annals of the New York Academy of Science, 977, 129-134.

Langa, K. M., Foster, N. L., \& Larson, E. B. (2004). Mixed dementia: emerging concepts and therapeutic implications. Journal of the American Medical Association, 23, 2901-2908.

Martin, R., \& Miller, M. (2002). Sentence comprehension deficits: interactions of syntax, semantic and working memory. In A. Hills (Ed.), The handbook of adult language disorders (pp. 295-310). Hove, UK: Psychology Press.

Maxim, J., \& Bryant, K. (Eds.). (2006). Communication disability in the dementias. London: Whurr.

Neuhaus, E., \& Penke, M. (2008). Production and comprehension of wh-questions in German Broca's aphasia. Journal of Neurolinguistics, 21, 150-176.

Neuropathology Group of the Medical Research Council Cognitive Function and Ageing Study (2001). Pathological correlates of late-onset dementia in a multicentre, community-based population in England and Wales. The Lancet, 357, 169-175. 
Pesetsky, D. (1987). Wh-in-situ: movement and unselective binding. In E. J. Reuland, \& A. G. B. ter Meulen (Eds.), The representation of (in)definiteness (pp. 98-129). Cambridge, MA: MIT Press.

Rochon, E., Waters, G. S., \& Caplan, D. (2000) Working memory and sentence comprehension in patients with Alzheimer's disease. Journal of Speech, Language and Hearing Research, 43, 395-413.

Saddy, D. (1995). Variables and events in the syntax of agrammatic speech. Brain and Language, 50, 135-150.

Salis, C. (in press). Processing of wh-questions in a case of posterior cortical atrophy. International Journal of Speech-Language Pathology.

Salis, C., \& Edwards, S. (2008). Comprehension of $w h$-questions and declarative sentences in agrammatic aphasia: The set partition hypothesis. Journal of Neurolinguistics, 21 (5), 375-399.

Thompson, C. K., Tait, M. E., Ballard, K. J., \& Fix, S. C. (1999). Agrammatic aphasic subjects' comprehension of subject and object extracted wh questions. Brain and Language, 67, 169-187.

van der Meulen, I., Bastiaanse, R., \& Rooryck, J. (2002). Wh-movement in French agrammatism. Brain and Language, 83, 184-187.

Waters, G., Rochon, E., \& Caplan, D. (1998). Task demands and sentence comprehension patterns in patients with dementia of the Alzheimer's type. Brain and Language, 62, 361-397.

Wechsler, D. (1987). Wechsler memory scale (revised). London: The Psychological Corporation. 